\title{
Morphological variability in the Cuatro Cienegas cichlid, Cichlasoma minckleyi
}

\author{
J. TRAPANI \\ Museum of Palaeontology and Department of Geological Sciences, University of Michigan, \\ 1109 Geddes Road, Ann Arbor, MI 48109-1079, U.S.A.
}

(Received 20 June 2001, Accepted 25 October 2002)

\begin{abstract}
The endemic cichlids of the Cuatro Cienegas Basin, Coahuila, Mexico are currently grouped in a single polymorphic species, Cichlasoma minckleyi. Two morphs of C. minckleyi were distinguished largely by features of the trophic apparatus, especially the pharyngeal dentition. Variation in body shape, based upon analysis of a set of linear measures, was continuous and did not allow recognition of discrete morphs. Individuals raised in the laboratory on several different diets indicated that trophic morphology had an important genetic component. Individuals raised in the laboratory, however, did not differentiate to the degree seen in comparably sized individuals collected at Cuatro Cienegas. This may be because snails used as food in the experiments were not as hard as endemic snails and indicated that some aspects of trophic morphology were also dependent upon environmental cues.

(C) 2003 The Fisheries Society of the British Isles
\end{abstract}

Key words: cichlids; evolution; genetics; pharyngeals; phenotypic plasticity; polymorphism.

\section{INTRODUCTION}

The Cuatro Cienegas Basin $\left(26^{\circ} 59^{\prime} \mathrm{N} ; 102^{\circ} 05^{\prime} \mathrm{W}\right)$, Coahuila, Mexico has a long history of isolation and environmental stability (Meyer, 1973), and contains a highly endemic fauna (Taylor \& Minckley, 1966; Minckley, 1969). The one recognized cichlid species endemic to the basin, Cichlasoma minckleyi Kornfield \& Taylor, exhibits a wide range of trophic and body form morphologies. Debate continues over whether C. minckleyi constitutes a single polymorphic species (Sage \& Selander, 1975; Kornfield \& Taylor, 1983) or comprises a small species flock (R.R. Miller, pers. comm.; W.L. Minckley, pers. comm.).

The first studies to document the diversity of cichlids living in sympatry within the Cuatro Cienegas Basin equated each morph with a biological species (Taylor \& Minckley, 1966; LaBounty, 1974; R.R. Miller, pers. comm.). Subsequent electrophoretic work illustrated that genetic differences between morphs were small (Kornfield \& Koehn, 1975), and more importantly, that different morphs at the same localities showed greater similarity than the same morph at different localities (Sage \& Selander, 1975). This provided strong evidence that the morphs might constitute a single biological species. Sage \& Selander (1975) concluded that, in

Tel.: +1734764 0489; fax: +17349361380; email: jtrapani@umich.edu 
contrast to African cichlids, the trophic radiation of Cuatro Cienegas cichlids had occurred without development of reproductive isolation. Field observations of the trophic apparatus of mating individuals by Kornfield et al. (1982) supported this assertion; they found that $57 \%$ of males and females from collected mating pairs (19 of 33) had different trophic morphologies. Therefore, Kornfield \& Taylor (1983) grouped all endemic Cuatro Cienegas cichlids into the single species, C. minckleyi.

Yet, consolidation of Cuatro Cienegas cichlids into a single species on these grounds did not satisfy some (Minckley, 1984; R.R. Miller, pers. comm.). Part of the reason for this continuing disagreement is that morphological variability has not been quantitatively documented for large samples, nor has there been any investigation of the genetic and environmental basis of the variation. This study attempts to address these shortcomings.

Most workers have placed C. minckleyi into several discrete morphs. Two morphs were documented by Kornfield \& Koehn (1975), Kornfield et al. (1982), and Liem \& Kaufman (1984); they were termed 'molariform' or 'papilliform' in reference to pharyngeal tooth shape. Molariform teeth are broad and flat, and are often accompanied by robust pharyngeal bones and muscles (Fig. 1). Cichlids with molariform pharyngeals are often thought to be specialists in crushing hard shells. In contrast, papilliform teeth are fine and conical, and are usually associated with smaller, more gracile pharyngeals. Papilliform cichlids are often thought to be detritivores and feed on softer food diets. Taylor \& Minckley (1966), Minckley (1969), Sage \& Selander (1975) and Stephens (1997) recognized three morphs: molariform and papilliform morphs, as well as a 'piscivorous' (fish-eating) morph characterized by a fusiform shape and slender body. Four morphs were distinguished by LaBounty (1974) and Kornfield \& Taylor (1983). These morphs possess all four

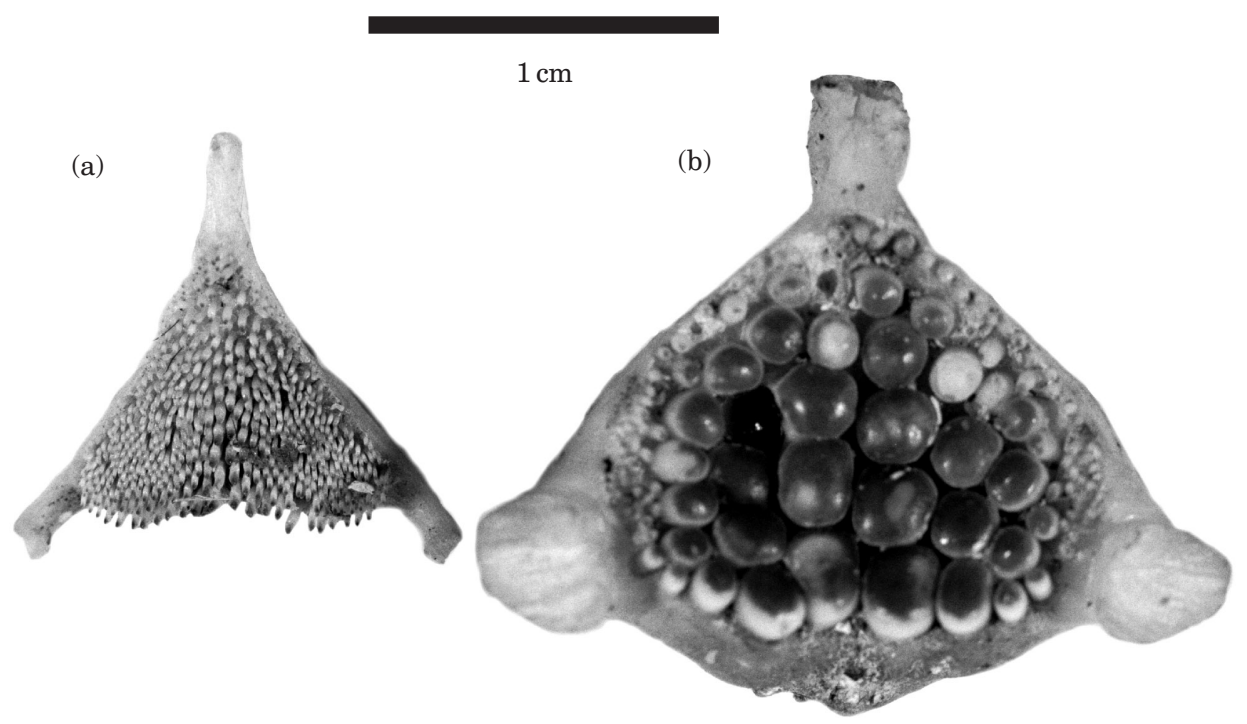

FIG. 1. Lower pharyngeals (fused fifth ceratobranchials) of (a) papilliform (UMMZ 198937-1; $L_{\mathrm{S}}=112.5 \mathrm{~mm}$ ) and (b) molariform (UMMZ 198947-1; $\left.L_{\mathrm{S}}=121.6 \mathrm{~mm}\right)$ Cichlasoma minckleyi. 
combinations of papilliform or molariform pharyngeal dentitions and deep or slender bodies.

Documenting characters contributing to variation has generally been less contentious than determining number of morphs. As in African cichlids, differences generally involve traits related to the trophic apparatus (Greenwood, 1981). In C. minckleyi, meristic characters (e.g. numbers of fin rays, scales and vertebrae) and oral dentition do not vary between morphs (LaBounty, 1974; Kornfield \& Taylor, 1983). Pharyngeal bones and dentition, however, do contribute to differences between morphs. Neurocranial measures related to the pharyngeals (e.g. skull width and size of pharyngobranchial apophysis; Kornfield \& Taylor, 1983) are also thought to reflect differences. In addition, certain aspects of body shape (e.g. head length and width and body depth) are accepted by some workers as differentiating morphs. Gut lengths also vary between morphs (LaBounty, 1974; Sage \& Selander, 1975; Kornfield \& Taylor, 1983). Very few quantitative studies documenting morphological differences, however, have been published.

Many cichlids exhibit a high degree of morphological plasticity [e.g. premaxillae of the African Haplochromis squamipinnis Regan, Witte, 1984; skull and body form of Neotropical Geophagus brasiliensis (Quoy \& Gaimard) and Geophagus steindachneri Eigenmann \& Hildebrand,Wimberger, 1991, 1992]. When plasticity is expressed as discontinuous variation, polymorphism results (Clark, 1976). Trophic polymorphism often reflects ecological (usually dietary) differentiation. Laboratory studies have documented this phenomenon both in African (e.g. Astatoreochromis alluaudi Pellegrin, Greenwood, 1965; Huysseune et al., 1994; Huysseune, 1995) and Neotropical [Cichlasoma managuense (Günther), Meyer, 1987] cichlids. Development of different phenotypes may be induced by feeding individuals foods of differing hardnesses (Meyer, 1990a; Huysseune, 1995). Individuals of these taxa fed hard foods (e.g. snails) often develop robust pharyngeals, hypertrophied musculature and molariform teeth. Neurocranial anatomy integrated with the pharyngeals is often altered in these forms as well (Smits et al., 1996).

Both LaBounty (1974) and Sage \& Selander (1975) mentioned that C. minckleyi individuals raised in the laboratory under different dietary regimes exhibit plasticity. Stephens \& Hendrickson (2001) noted that a molariform by molariform cross produced individuals with molariform, papilliform and intermediate morphologies. These results indicate that trophic morphology is not entirely controlled by diet, and must have some genetic component. Both Sage \& Selander (1975) and Kornfield \& Taylor (1983) hypothesized that the polymorphism was under singlelocus genetic control, with the papilliform allele dominant. Studies of stomach contents and habitat segregation in the field indicate some trophic differences between individuals with dissimilar morphologies, but these differences are not clear-cut or consistent (Sage \& Selander, 1975; Earthwatch Project, 1999) and there is considerable dietary overlap (Kornfield \& Taylor, 1983). Laboratory experiments also indicate that the degree of dietary differentiation between morphs may be dependent upon availability of various food resources (Liem \& Kaufman, 1984).

\section{MATERIALS AND METHODS}

Fish in this study came from collections at the University of Michigan Museum of Zoology (UMMZ) and Arizona State University (ASU). Material was collected from localities 


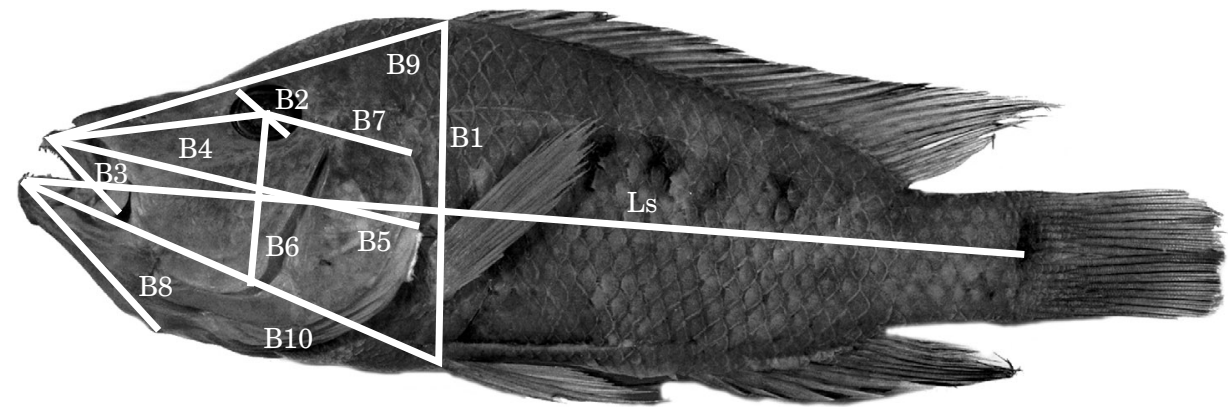

FIG. 2. Body form measurements: standard length $\left(L_{\mathrm{S}}\right)$; B1, body depth (pectoral to pelvic fin); B2, eye width; B3, upper jaw length; B4, snout length; B5, head length; B6, cheek depth; B7, postorbital length; B8, lower jaw length; B9, predorsal length; B10, prepelvic length. Postorbital head width (B11) and maximum head width (at opercules, B12) were also measured but are not shown.

within the Cuatro Cienegas Basin between 1939 and 1975. Individuals used in the feeding experiments were collected in 1975 and raised at the University of Michigan.

To assess body form, 12 measurements were made (to the nearest $0.1 \mathrm{~mm}$, using dial calipers) on a sample of 193 preserved individuals ranging from 50 to $169 \mathrm{~mm}$ standard length, $L_{\mathrm{S}}$ (Fig. 2). Eight neurocranial measurements were made on a sample of 35 completely disarticulated skeletons and three measurements were made on the oral jaws (Fig. 3) of these 35 skeletons and an additional 33 partially disarticulated skeletons. Eight measurements on the fused fifth ceratobranchials (i.e. lower pharyngeals), including six linear measurements (made to the nearest $0.01 \mathrm{~mm}$ with an ocular micrometer) and two tooth counts (Fig. 4) were made on all individuals.

Principal component analyses (PCA) were used to investigate the data. PCA is superior to other methods (such as canonical variates analysis) for answering the questions raised in this study because PCA does not require a priori assumptions about number of phenotypic or taxonomic groups, group membership of individuals, or any prior knowledge of the distribution of C. minckleyi individuals in multivariate morpho-space (Neff \& Smith, 1978). PCA character loadings accurately reflect relative within- and between-groups variation (Bookstein et al., 1985).

PCA was performed on the correlation matrix of log-transformed data (tooth counts were not logged) using SPSS 8.0 Statistical Software. Four separate analyses were done to investigate number of morphs present and the variables distinguishing them: (1) body form plus pharyngeal measurements ( 20 variables, $n=180$ : P3, maximum length of ceratobranchials at their symphysis, was excluded from this analysis because it was broken off on many individuals); (2) body form measurements only (13 variables, $n=193$ ); (3) neurocranium, jaw and pharyngeal measurements (21 variables, $n=30$ ); (4) neurocranium and jaw measurements only (13 variables, $n=33$ ). Each analysis contains individuals from several localities; however, both morphs are represented at most of the localities.

To assess the relative contributions of genetics and phenotypic plasticity to trophic morphology, six broods were collected from Los Corrales, Cuatro Cienegas in 1975 and raised at the University of Michigan. Los Corrales is a stream site on the Rio Mesquites, where cichlids occur at moderate density. Cichlasoma minckleyi is highly territorial; at this locality males guard territories containing several female nests, and each female guards her own nest (J.N. Taylor, pers. comm.). These factors make it extremely unlikely that any brood represented the offspring of more than a single male-female pair. In some cases, it was possible to capture the parents briefly and roughly assess their trophic morphology with an otoscope. Parents were not preserved because they were part of an ongoing behavioural study.

Broods were brought to the University of Michigan and raised in partitioned tanks. Four of the six broods (broods 3, 4, 5 and 6) were split into three sub-groups each and fed diets of different hardnesses: shrimp (soft food), 'stock' (commercial pellets of intermediate hardness) and snails (hard food). Snail food consisted of Heliosoma sp. Attempts were made 


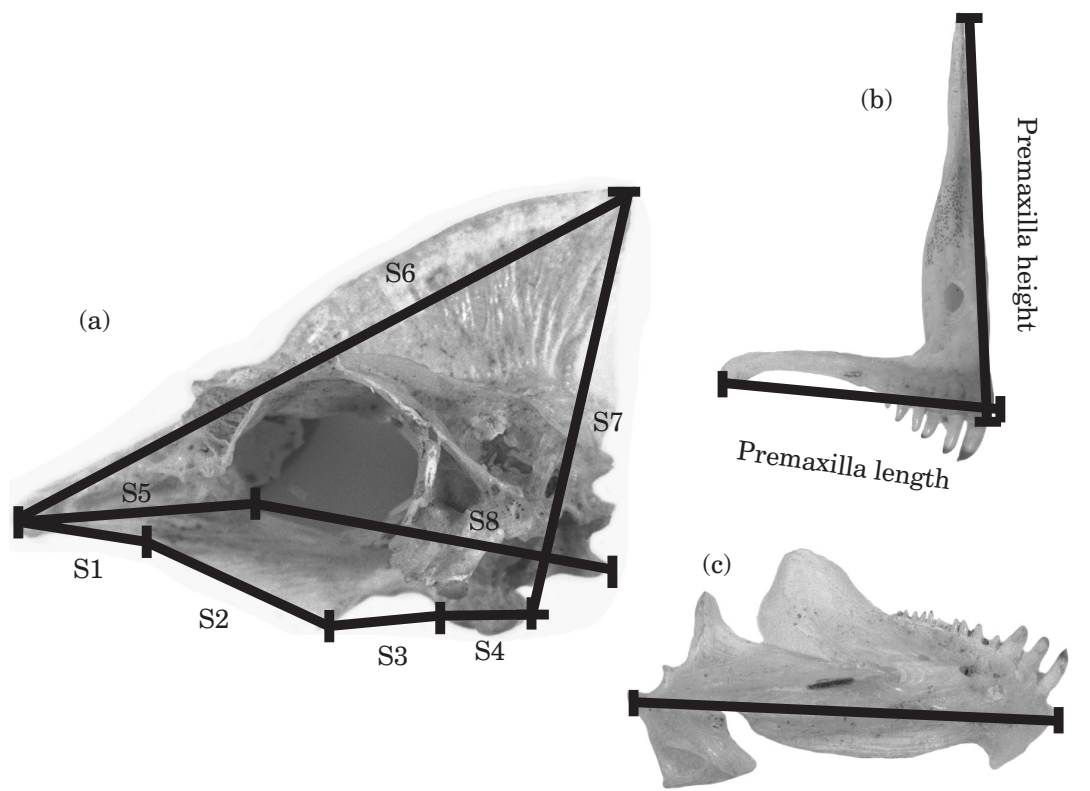

Lower jaw length

FIG. 3. Skull and jaw measurements: (a) neurocranium: S1, anterior tip of snout to maxillary suture; S2, maxillary suture to ventral crest of parasphenoid; S3, ventral crest of parasphenoid to pharyngobranchial apophysis; S4, length of pharyngobranchial apophysis; S5, anterior tip of snout to ventral margin of orbit; S6, anterior tip of snout to tip of neurocranial crest; S7, tip of neurocranial crest to pharyngobranchial apophysis; S8, ventral margin of orbit to first vertebral articulation; postorbital head width (not shown), (b) premaxilla and (c) lower jaw.

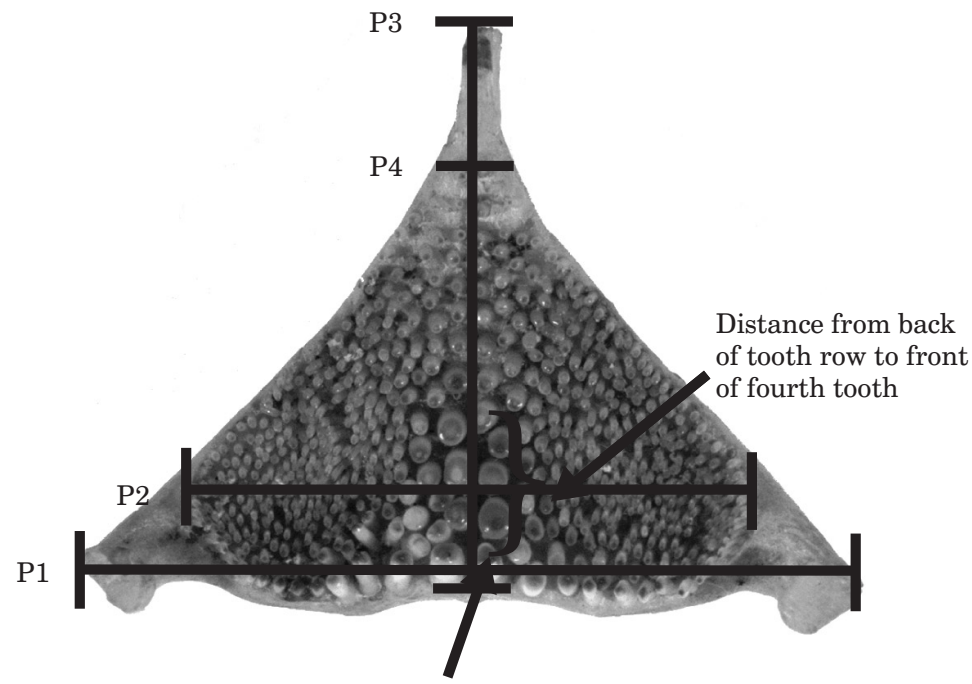

Maximum tooth diameter

FIG. 4. Fifth ceratobranchial measurements: P1, maximum width at rami; P2, maximum width of dental area; P3, maximum length at symphysis; P4, maximum length of dental area at symphysis; number of teeth mediolaterally along back row; number of teeth anterioposteriorly along fusion; mediolateral diameter of largest tooth; anteroposterior distance from back of tooth row to front of fourth tooth from back. 
to standardize snails fed to brood sub-groups, but there was some variation in size and hardness. Heliosoma sp. possesses thinner shells than Cuatro Cienegas snails; this difference in hardness may have affected the trophic morphologies produced by the experiments. The remaining two broods (brood 1 and an $\mathrm{M} \times \mathrm{M}$ brood) were fed stock food. Fish were removed at intervals and preserved. Individuals ranged in size from 25 to $68 \mathrm{~mm} L_{\mathrm{S}}$. Pharyngeal dimensions and tooth diameters were measured and tooth numbers counted (Fig. 4) on 283 individuals from the six broods.

PCA was performed on these data (eight variables, $n=262$ ) to investigate whether clustering occurred with respect to diet and brood. The General Linear Model option on SPSS 8.0 Statistical Software was used to analyse the four broods raised on different diet treatments. MANCOVA and univariate ANCOVAs were performed separately for each brood on logtransformed measurements (tooth counts were not transformed) with $\log L_{\mathrm{S}}$ as the covariate and diet as a fixed factor to look for diet effects and diet-by-size interactions. Standard length was used as the covariate to serve as a univariate indicator of relative size. Diet effects indicate that intercepts of growth trajectories are significantly different. Diet-by-size interactions indicate that slopes of growth trajectories are significantly different (Wimberger, 1991, 1992).

A similar analysis was performed on a pooled data set consisting of all four broods raised on different diets. In this analysis, both diet and brood were treated as factors. This analysis allowed investigation of diet and brood effects as well as diet $\times$ brood interactions. Significant brood effects indicate genetic influences (heritability). Diet-by-brood interactions mean that broods are responding differently (either in direction or magnitude) to the same diet (Wimberger, 1991, 1992; Robinson \& Wilson, 1996). Because the eight measures on each fish were not independent of one another, a corrected critical value of $P<0 \cdot 05 / 8=0 \cdot 00625$ was used to interpret the significance of the results.

\section{RESULTS}

Principal component analyses indicates that there were two morphs in this sample (Fig. 5). To remove size from the components and illustrate bimodality, the sample was divided into two groups based upon PC II scores and this component was sheared (using the covariance matrix, with tooth counts excluded; Humphries et al., 1981; Bookstein et al., 1985; Rohlf \& Bookstein, 1987) with the SHEAR programme (N. MacLeod, http://life.bio.sunysb.edu/morph/). Distributions of sheared PC II scores are shown as histograms in Fig. 5, and differ significantly from normality [Kolmogorov-Smirnov one sample test against normal distribution; Fig. 5(b): $P=1.19 \times 10^{-7}$; Lilliefors $P<0.00001$; Fig. 5(d): $P=1.19 \times 10^{-7}$; Lilliefors $P=0 \cdot 0036]$.

Morphs were differentiated by numbers of teeth (fewer teeth in the molariform morph), maximum tooth diameter (larger in the molariform morph), distance from the back of the tooth row to the front of the fourth tooth (larger in the molariform morph) and relative dimensions of S3 (ventral crest of parasphenoid to pharyngobranchial apophysis) and S4 (length of pharyngobranchial apophysis). The former is larger in the papilliform morph; the latter is larger in the molariform morph.

Analysis 1 (body form plus pharyngeals) showed two clusters of individuals in principal component (PC) space, with several specimens exhibiting intermediate phenotypes. Clusters were distinguished largely by aspects of the pharyngeal dentition [Fig. 5(a) and Table I]. Maximum length of the fifth ceratobranchials along their symphysis (variable P3) was excluded from this analysis. An additional analysis including this variable showed the same two clusters with intermediates as analysis 1, but the sample size was reduced to 119 individuals. Variable P3 also had 

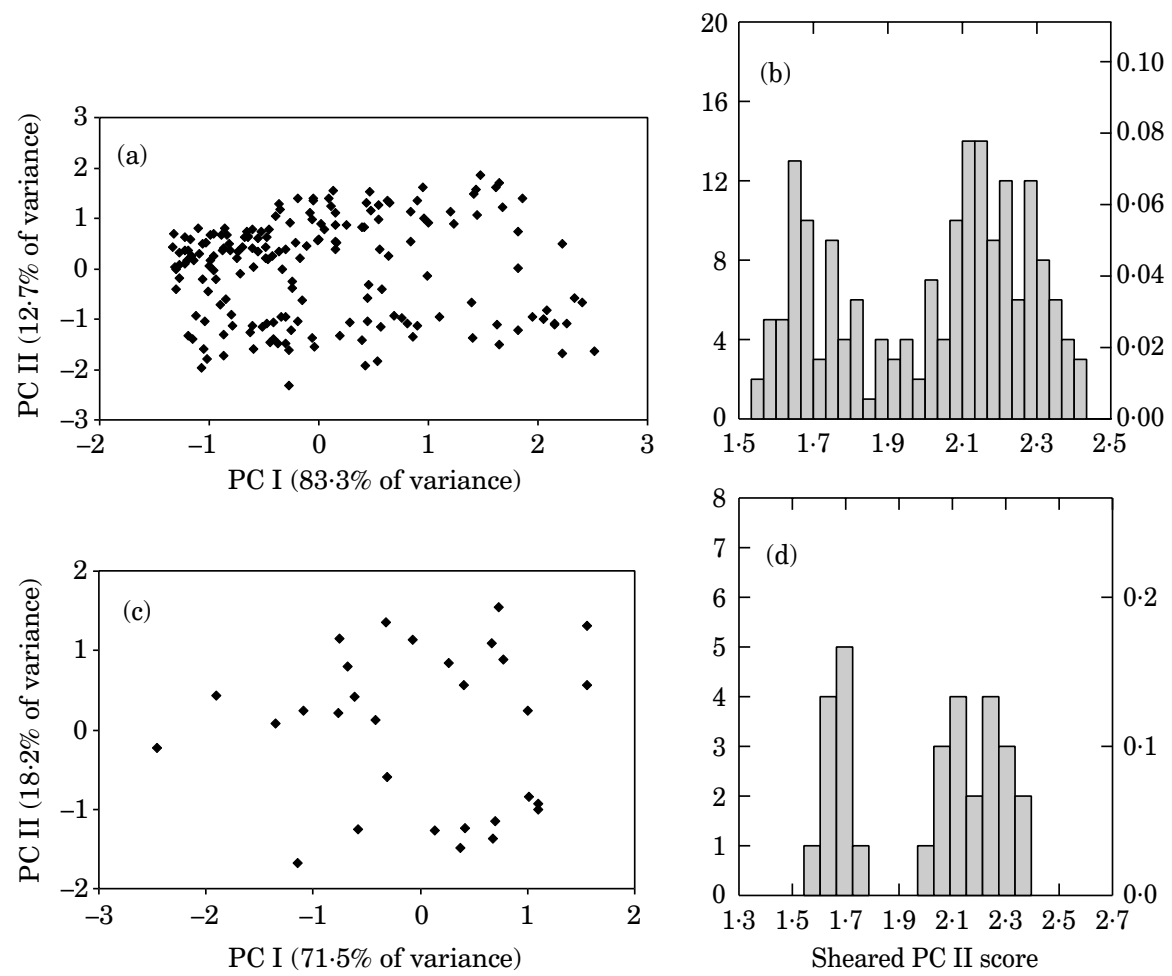

FIG. 5. Principal component analyses of Cichlasoma minckleyi morphology. (a) Analysis 1: body form plus pharyngeal measures (20 variables, $n=180$ ), (b) frequency distribution of sheared PC II scores from analysis 1, (c) analysis 3: neurocranium, jaw and pharyngeal measures (21 variables, $n=30)$ and (d) frequency distribution of sheared PC II scores from analysis 3.

a very low factor loading on PC II in this analysis; therefore, excluding P3 from analysis 1 did not alter its outcome. Analysis 2 (body form only) indicated that linear measures of body form alone were not sufficient to distinguish morphs. In this analysis, PC I was highly correlated with size (all loadings positive and $>0.9$ ) and accounted for nearly $98 \%$ of the variance. PC II accounted for $<1 \%$ of the variance (Table I). Analysis 3 (neurocranium, jaws and pharyngeals) distinguished two morphs on the basis of pharyngeal dentition and several neurocranial measures [Fig. 5(c) and Table I]. Analysis 4 showed that neurocranial measures alone will distinguish two morphs, with skull measures related to pharyngeal support (S3 and S4) contributing most of the discriminatory variability (Table I).

Individuals from the feeding experiments formed one large cluster in PC space (Fig.6). The variables contributing most significantly to differentiation along PC II were, as in previous analyses, aspects of the pharyngeal dentition (tooth sizes and numbers; Table I). Distribution of individuals within the cluster depended upon the primary determinant of trophic morphology. If morphology is largely the result of diet-induced phenotypic plasticity, individuals should group by diet. In contrast, if morphology is largely determined by genetics, individuals should group by brood. No grouping by diet was shown [Fig. 6(a)], but individuals grouped by brood [Fig. 6(b)]. 


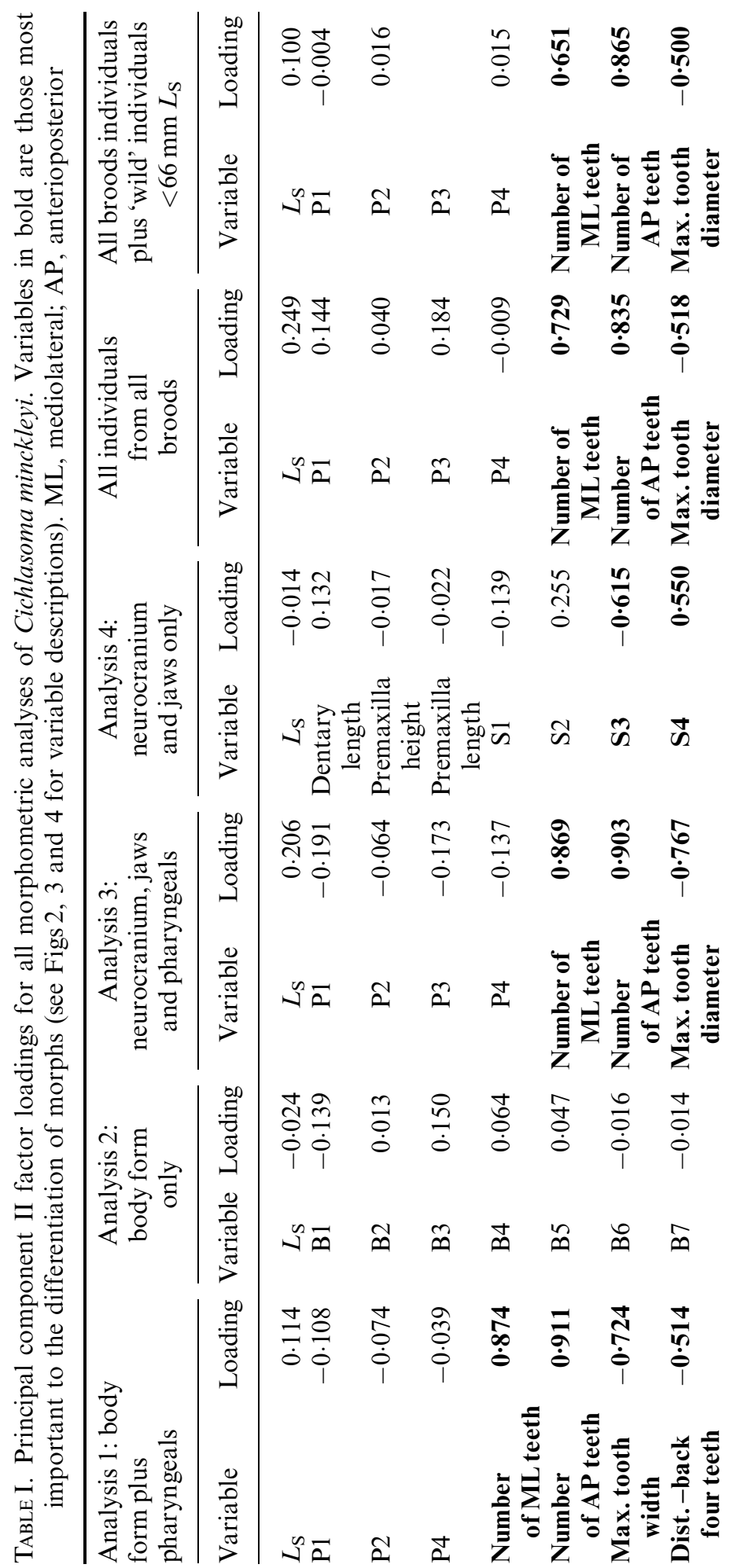


$\ddot{\dot{\theta}}$

葛

$\stackrel{+}{\dot{1}}$

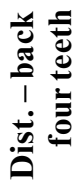

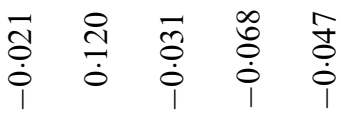

$\approx \approx$ is $\infty \frac{0}{\frac{0}{3}}$

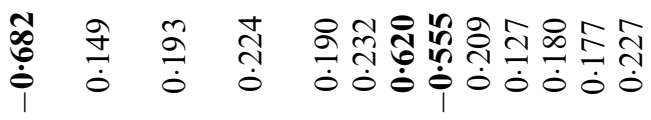

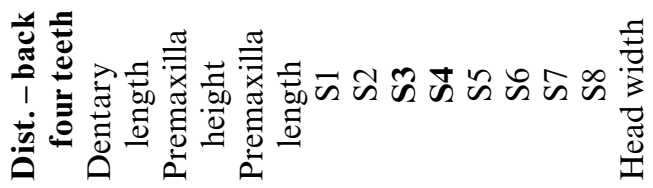

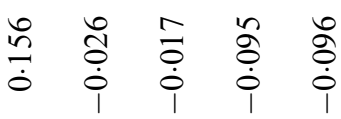

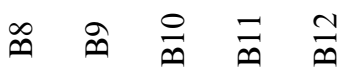

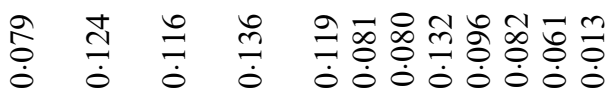

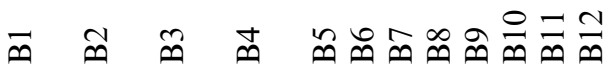




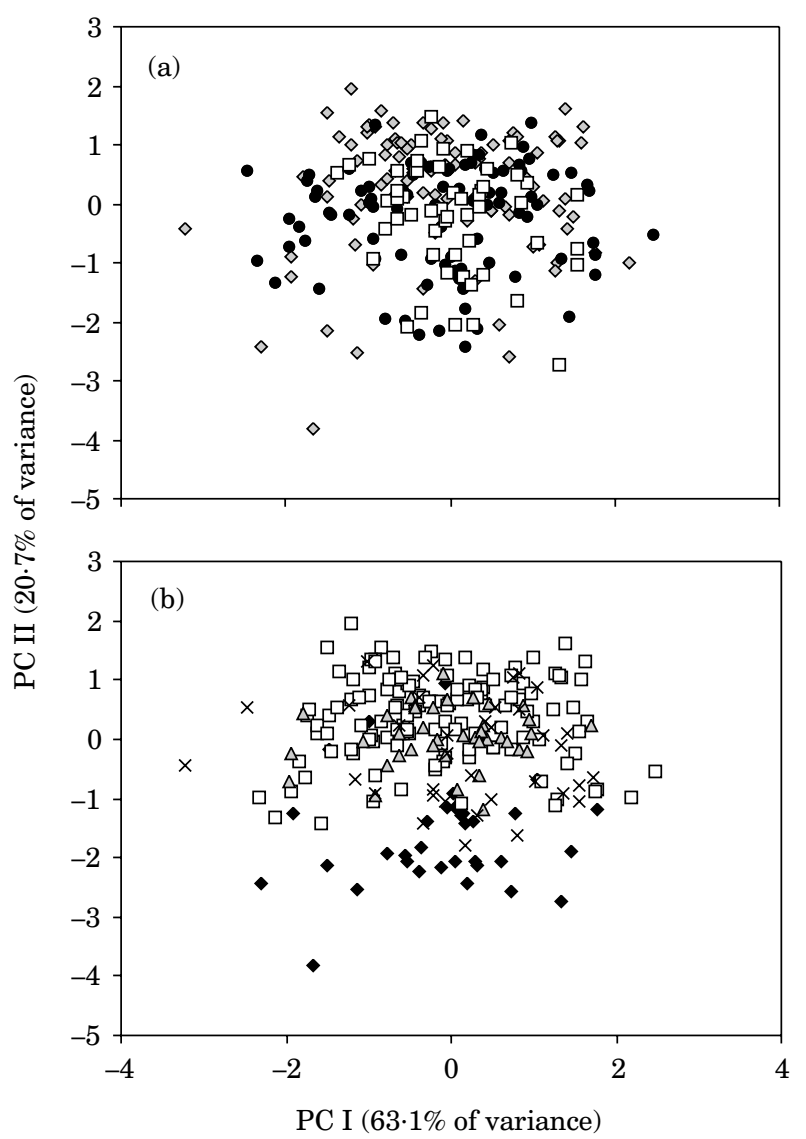

FIG. 6. Principal component analysis of trophic morphologies of individuals raised in the feeding experiment: (a) diet ( $\diamond$, shrimp; •, snails; $\square$, stock) and (b) brood ( $\times$, B3; $\Delta, \mathrm{B} 4 ; \square, \mathrm{B} 5 ; \diamond, \mathrm{B} 6)$.

MANCOVA results indicated significant diet $\times$ size interaction, but no significant diet effects, within each brood (Table II). Univariate ANCOVAs show that only brood 4 had variables exhibiting a significant diet effect (Table III). In all broods, pharyngeal dimensions, maximum tooth diameter (except brood 6)

TABLE II. MANCOVA results for experimental Cichlasoma minckleyi broods. Values in bold indicate that $P$ is significant $(<0.00625)$

\begin{tabular}{|c|c|c|c|c|c|c|}
\hline & \multicolumn{3}{|c|}{ Diet effects } & \multicolumn{3}{|c|}{ Diet-by-size interaction } \\
\hline & Wilks' $\lambda$ & $F$ & $P$ & Wilks' $\lambda$ & $F$ & $P$ \\
\hline Brood 3 & 0.449 & 1.417 & $0 \cdot 176$ & $0 \cdot 010$ & $11 \cdot 053$ & $0 \cdot 000$ \\
\hline Brood 4 & $0 \cdot 353$ & $2 \cdot 222$ & 0.016 & 0.018 & $9 \cdot 396$ & $0 \cdot 000$ \\
\hline Brood 5 & 0.760 & $2 \cdot 166$ & 0.007 & $0 \cdot 031$ & $33 \cdot 278$ & $0 \cdot 000$ \\
\hline Brood 6 & 0.519 & 1.066 & 0.413 & $0 \cdot 055$ & $4 \cdot 600$ & $0 \cdot 000$ \\
\hline
\end{tabular}




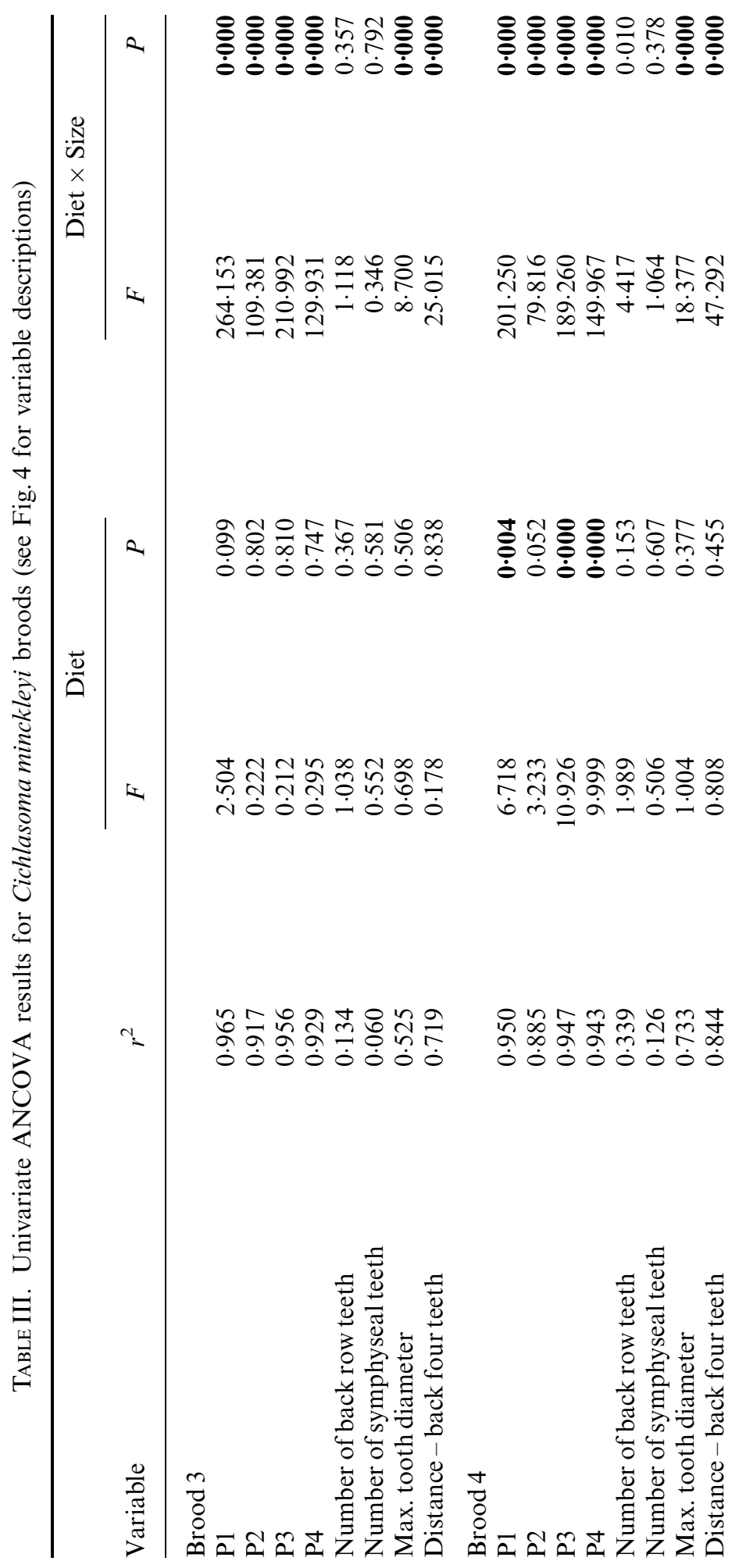




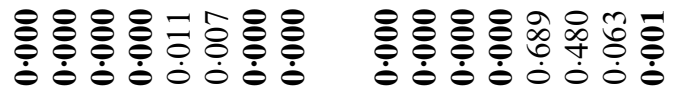

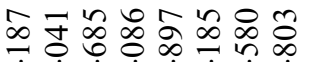

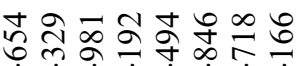

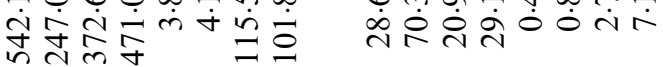

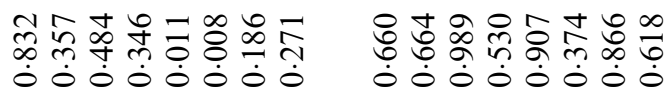

চ ำ

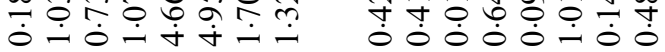

๓ૅ

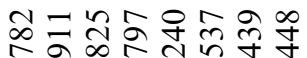
ㅇํㅇ $\dot{0} \dot{0} \dot{0} \hat{0} \dot{0}$

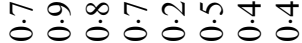

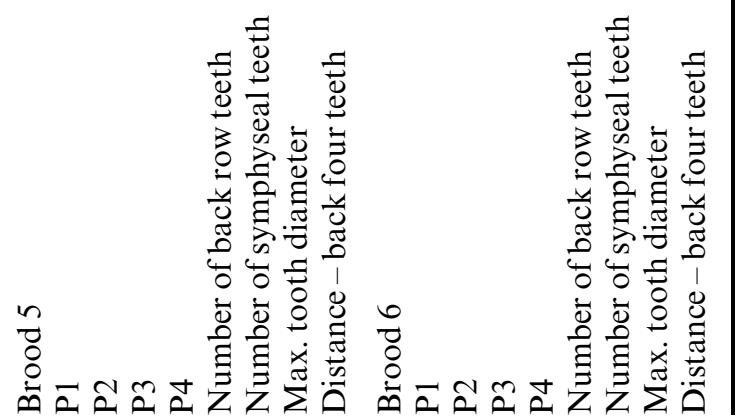



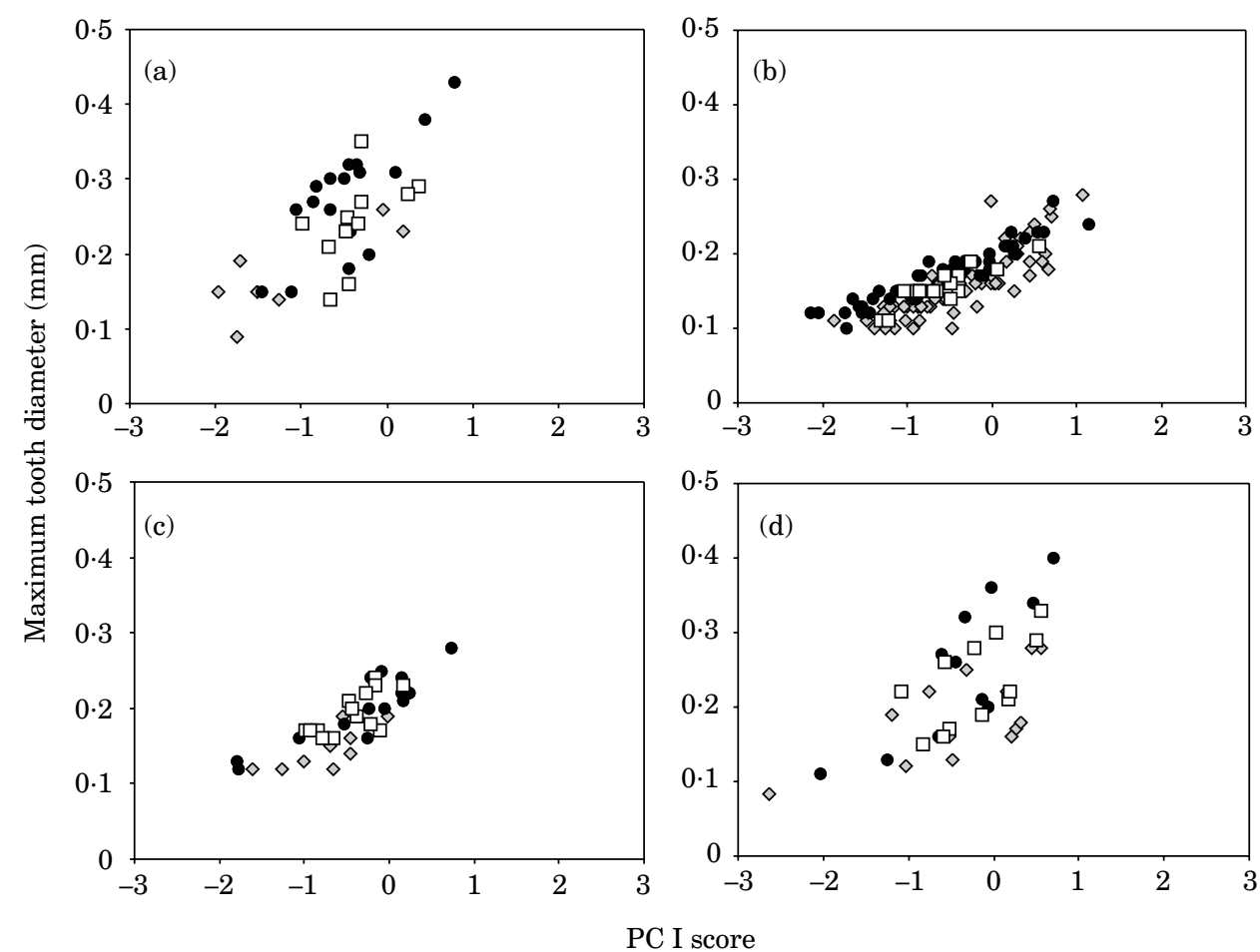

FIG.7. Maximum tooth diameter plotted against PC I for individuals raised in the feeding experiments: (a) brood 6 (b) brood 5 (c) brood 4 (d) brood 3. $\diamond$, shrimp-fed; $\square$, stock-fed; $\bullet$, snail-fed individuals. For all broods, individuals fed harder food tended to have larger teeth. In brood 3, each dietary group formed two distinct clusters. (This is also true, to some extent, in the individuals fed snails in brood 6.)

and distance from back of the tooth row to the front of the fourth tooth exhibited significant diet $\times$ size interactions. This means that individuals within a brood fed different diets differ significantly in rates of growth of pharyngeal bones and teeth, but (with a few exceptions in brood 4) not in intercepts of their ontogenetic trajectories. Individuals fed snails were the largest within each brood for all linear measures of bones and teeth, with one exception.

Diet also produced interesting, though statistically non-significant, variation in maximum tooth diameter for individuals within a brood (Fig.7). Within broods, fish fed shrimp generally had the narrowest teeth, fish fed stock food had teeth of intermediate sizes, and fish fed snails had the broadest teeth. When all broods were considered together, there were two trajectories for each diet type. Individuals fed snails from broods 3 to 6 , as well as individuals from brood 1 and the $\mathrm{M} \times \mathrm{M}$ brood are shown in Fig. 8. All individuals from broods 1, 4 and 5 fell along one trajectory, and individuals from the $\mathrm{M} \times \mathrm{M}$ brood (with one exception) fell along the other. Individuals from broods 6 and 3 fell along both trajectories. These patterns were repeated in the responses of broods 3-6 to each of the three diets. Comparison of regressions $(95 \%$ CI) for individuals in each brood plotted in Fig. 8 (Table IV) indicated a more complex pattern: broods 6,3 and $\mathrm{M}$ did not differ from one another, whereas the other broods (broods 5, 4 and 1) each differ from all other 


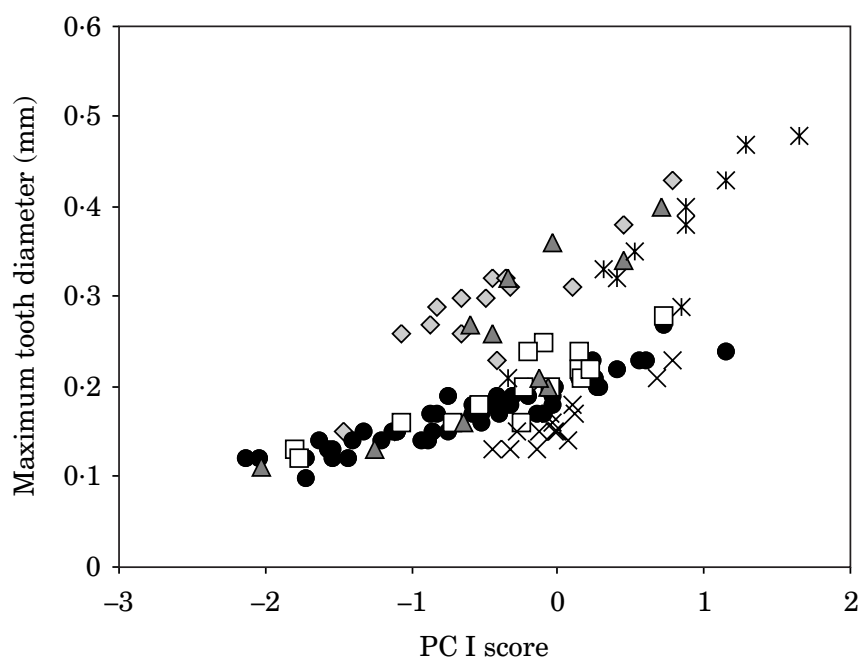

FIG. 8. Maximum tooth diameter plotted against PC I for individuals from broods $3(\Delta), 4(\square), 5(\bullet)$ and $6(\diamond)$ fed snails, as well as individuals from brood $1(*)$ and the $\mathrm{M} \times \mathrm{M}$ brood $(\times)$. See Table IV.

broods in either slope or intercept. It is not clear how informative comparison of regression lines is when points within a brood appear to fall along two distinct trends.

MANCOVA results for the pooled data set (four broods fed on different diets) indicated that diet effects were non-significant $(P=0.226)$ whereas both brood effects and diet-by-brood interactions were highly significant (brood: Wilks' $\lambda=0 \cdot 254, F_{24,636}=16 \cdot 022, P=0.000$; diet $\times$ brood: Wilks' $\lambda=0.541, F_{48,1082}=2.992$, $P=0.000$ ). Univariate ANCOVAs (TableV) also indicated no significant diet effects. TableV also shows that all variables had a significant brood effect.

TABLE IV. Comparison of regression slope and intercept coefficients for Cichlasoma minckleyi maximum tooth diameter and PC I calculated for different broods (see Fig. 8). $\mathrm{Y}$, significant differences at $P=0.05 ; \mathrm{N}$, regression coefficients are not significantly different

\begin{tabular}{|c|c|c|c|c|c|}
\hline & Brood 6 & Brood 5 & Brood 4 & Brood 3 & Brood M \\
\hline \multicolumn{6}{|l|}{ Slopes } \\
\hline Brood 5 & $\mathrm{Y}$ & & & & \\
\hline Brood 4 & $\mathrm{~N}$ & $\mathrm{~N}$ & & & \\
\hline Brood 3 & $\mathrm{~N}$ & $\mathrm{Y}$ & $\mathrm{N}$ & & \\
\hline Brood M & $\mathrm{N}$ & Y & $\mathrm{Y}$ & $\mathrm{N}$ & \\
\hline Brood 1 & $\mathrm{~N}$ & $\mathrm{Y}$ & $\mathrm{N}$ & $\mathrm{N}$ & $\mathrm{N}$ \\
\hline \multicolumn{6}{|l|}{ Intercepts } \\
\hline Brood 4 & Y & $\mathrm{Y}$ & & & \\
\hline Brood 3 & $\mathrm{~N}$ & & $\mathrm{Y}$ & & \\
\hline Brood M & $\mathrm{N}$ & & & $\mathrm{N}$ & \\
\hline Brood 1 & $\mathrm{Y}$ & & $\mathrm{Y}$ & $\mathrm{Y}$ & $\mathrm{Y}$ \\
\hline
\end{tabular}


TABLEV. ANCOVA results for the pooled data set of Cichlasoma minckleyi individuals from broods raised on different diets (broods 3, 4, 5 and 6)

\begin{tabular}{|c|c|c|c|c|c|c|c|}
\hline \multirow[b]{2}{*}{ Variable } & \multirow[b]{2}{*}{$r^{2}$} & \multicolumn{2}{|c|}{ Diet } & \multicolumn{2}{|c|}{ Brood } & \multicolumn{2}{|c|}{ Diet $\times$ Brood } \\
\hline & & $F$ & $P$ & $F$ & $P$ & $F$ & $P$ \\
\hline Pharyngeal width & $0 \cdot 919$ & $0 \cdot 242$ & 0.785 & $8 \cdot 985$ & $0 \cdot 000$ & 3.949 & $0 \cdot 001$ \\
\hline $\begin{array}{l}\text { Dentigerous area } \\
\text { width }\end{array}$ & $0 \cdot 874$ & $0 \cdot 389$ & 0.678 & $23 \cdot 722$ & $0 \cdot 000$ & 4.647 & $0 \cdot 000$ \\
\hline Pharyngeal length & 0.895 & 0.957 & $0 \cdot 386$ & $8 \cdot 483$ & $0 \cdot 000$ & $6 \cdot 743$ & $0 \cdot 000$ \\
\hline $\begin{array}{l}\text { Dentigerous area } \\
\text { length }\end{array}$ & $0 \cdot 901$ & $0 \cdot 525$ & $0 \cdot 592$ & $4 \cdot 8126$ & $0 \cdot 000$ & $1 \cdot 346$ & $0 \cdot 238$ \\
\hline $\begin{array}{l}\text { Number of teeth } \\
\text { along back tooth row }\end{array}$ & $0 \cdot 288$ & $2 \cdot 260$ & $0 \cdot 107$ & $17 \cdot 251$ & $0 \cdot 000$ & $2 \cdot 087$ & $0 \cdot 056$ \\
\hline $\begin{array}{l}\text { Number of teeth } \\
\text { along suture }\end{array}$ & $0 \cdot 364$ & $3 \cdot 176$ & $0 \cdot 044$ & $28 \cdot 074$ & $0 \cdot 000$ & $4 \cdot 778$ & $0 \cdot 000$ \\
\hline $\begin{array}{l}\text { Maximum tooth } \\
\text { diameter }\end{array}$ & 0.696 & $0 \cdot 552$ & 0.576 & $63 \cdot 301$ & $0 \cdot 000$ & $1 \cdot 366$ & $0 \cdot 229$ \\
\hline $\begin{array}{l}\text { Distance from back of } \\
\text { tooth row to front } \\
\text { of fourth tooth }\end{array}$ & 0.730 & $0 \cdot 480$ & $0 \cdot 620$ & 85.493 & $0 \cdot 000$ & $2 \cdot 826$ & $0 \cdot 011$ \\
\hline
\end{tabular}

Four of the eight variables showed significant diet $\times$ brood interactions. These results corroborate the PCA and indicate that genetic (brood) effects were largely responsible for generating trophic morphologies observed in the experimental individuals.

To investigate the relationship of individuals raised in the feeding experiment to those in Cuatro Cienegas, an additional PCA was performed (Fig. 9) with all individuals from the six experimental broods $(n=262)$ as well as all individuals collected at Cuatro Cienegas of comparable size $\left(22-65 \mathrm{~mm} L_{\mathrm{S}} ; n=144\right.$, this analysis excluded measure P3). Variables of the pharyngeal dentition again had the highest factor loadings (Table I). 'Wild' individuals diverged in trophic morphology by c. $40 \mathrm{~mm} L_{\mathrm{S}}$ [Fig.9(b)]. A blind re-examination of 74 of the 80 of these 144
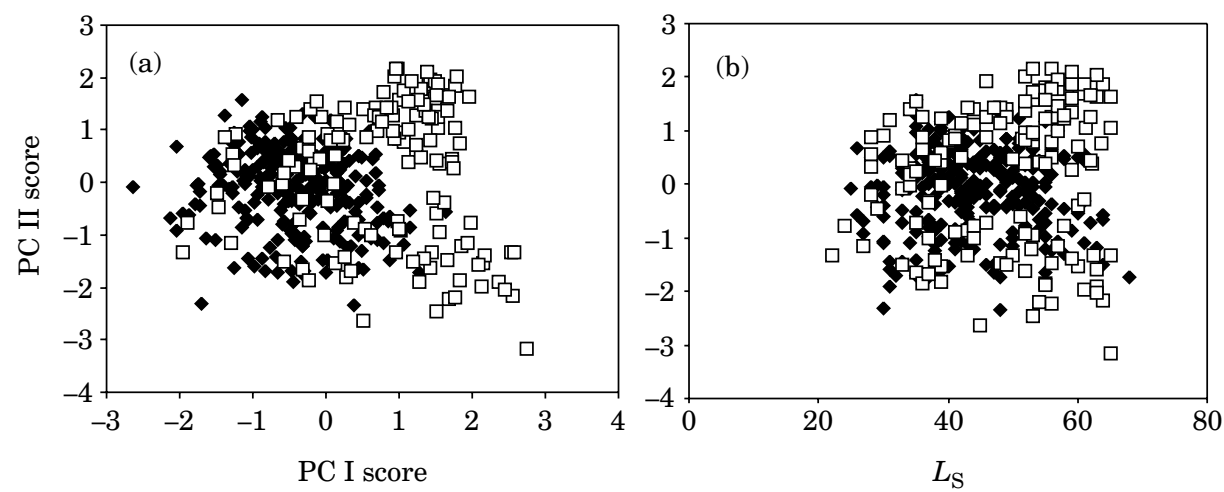

FIG. 9. (a) PC scores, and (b) standard length $v$. PC II scores for individuals from broods raised in the laboratory $(\diamond)$ compared with comparably sized individuals collected at Cuatro Cienegas $(\square)$. 
individuals $>50 \mathrm{~mm} L_{\mathrm{S}}$ (the other six were not associated with individualized tags so could not be matched with previously collected data) correctly classified 71 of them $(96 \%)$ as either papilliform or molariform. Visual classification was based on tooth size and shape as well as overall bone robusticity; tooth counts also provided nearly complete discrimination.

Broods fell both within and between the ranges of 'wild' morphs (Fig. 9). PC I scores, however, were systematically offset between 'wild' and brood individuals [Fig. 9(a)], and a plot of $L_{\mathrm{S}}$ against maximum tooth diameter [Fig. 9(b)] showed that the experiments, despite producing two types of fish, failed to produce fish 'molarized' to the same extent as fish in the wild (Fig. 10). This failure was attributed to the thin, easily crushed shell of Heliosoma relative to Cuatro Cienegas snails.

\section{DISCUSSION}

\section{NUMBER OF MORPHS OF C. MINCKLEYI}

PCA discriminated between two wild morphs, distinguished by characters of the pharyngeal dentition, as well as by two neurocranial measurements related to hypertrophication of the pharyngeals in molariform individuals. Several lines of evidence contributed to the conclusion that body form characters did not distinguish these morphs. First was the failure of PC analysis 2 to distinguish clusters on the basis of body form. Factor loadings for PC II in analysis 2 indicated that all variables contributed only weakly to that axis $(<0 \cdot 160$; Table I). The three variables with the strongest contribution to the variance were body depth, snout length and lower jaw length. Body depth, the character most likely to distinguish between deep- and narrow-bodied forms, showed a weak negative correlation with PC II. It is therefore expected that individuals with the highest PC II scores are most likely to be narrow-bodied. Individuals with the highest PC II scores (using several

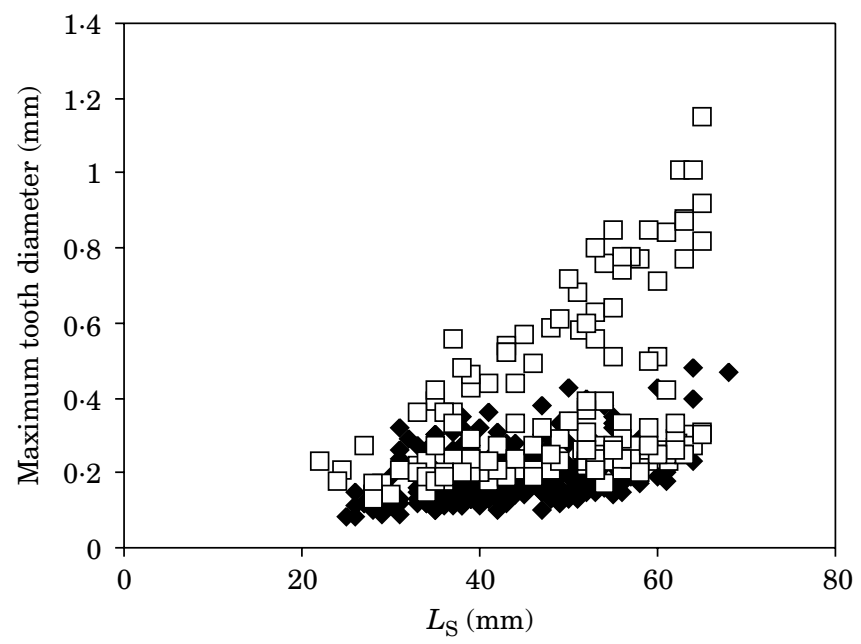

FIG. 10. Maximum tooth diameter and standard length plotted for individuals from broods raised in the laboratory $(\bullet)$ compared with comparably sized individuals collected at Cuatro Cienegas $(\square)$. 
different arbitrary cutoffs) in analysis 2 , however, did not cluster together in PC space when characters of the pharyngeal dentition were included (i.e. in analysis 1). The PC II scores (analysis 1) for these individuals fell within the range of both morphs, as well as in the intermediate range. Finally, there appeared to be little or no bimodality either in body depth $\left(n=193, r^{2}=0.9638\right)$ or head width $(n=193$ preserved, $r^{2}=0.9686 ; n=35$ skeletons; $\left.r^{2}=0.9311\right)$ as a function of $L_{\mathrm{S}}$. More sensitive techniques (e.g. geometric morphometrics) might pick out a discontinuity if one exists, but traditional distance-based morphometrics fails to do so.

\section{ROLE OF GENETICS AND PLASTICITY IN GENERATING MORPHOLOGY}

Differences in tooth numbers, sizes and bone hypertrophication between C. minckleyi morphs generally correspond to differences documented between morphs of other Cichlasoma species (Meyer, 1990a,b) as well as between morphs of A. alluaudi (Huysseune et al., 1994; Huysseune, 1995). Laboratory experiments indicate that genetics play a role in generating trophic morphology. Individuals cluster in multivariate space by brood, not by diet. Further, MANCOVA results indicated significant brood effects and non-significant diet effects. In addition, some characters showed significant diet $\times$ brood interactions, which means that different broods respond to the same diet in different ways. Genetics constrain variability such that, for example, certain individuals in some broods fed hard food will still develop smaller teeth than certain individuals in other broods fed soft food (Fig. 7). The puzzling results of prior experiments on C. minckleyi (e.g. development of 'molars' in fish not fed snails, Kornfield \& Koehn, 1975, molariform parents producing papilliform offspring, Stephens \& Hendrickson, 2001) make sense in this context.

There is also evidence to suggest an important role for phenotypic plasticity in determining trophic morphology, especially with respect to maximum tooth diameter. Diet has an effect within broods such that maximum tooth diameter is generally larger in individuals fed harder food (Fig.7). In addition, despite the development of two types of fish in the laboratory, the magnitude of differences between these types was small relative to differences seen between morphs at Cuatro Cienegas (Figs 9 and 10). A likely explanation for the failure of laboratory individuals to molarize to the degree seen at Cuatro Cienegas is that snail-fed individuals in the laboratory ate Heliosoma sp., which is thin-shelled and easy to crush relative to many Cuatro Cienegas snails, thus producing less mechanical stress on the pharyngeal apparatus during food processing (Vandewalle et al., 1994).

Trophic morphology thus results from interaction of direct genetic effects and environmentally induced plasticity. In the laboratory, some broods are capable of expressing the entire range of observed phenotypic variation in maximum tooth diameter, whereas others are only capable of expressing a limited sub-set. But individuals are capable of expressing only a sub-set of possible phenotypic variation present, regardless of their genetic background. An unanswered question remains: which individuals are capable of being molarized, given the proper environmental cue, to the extent seen at Cuatro Cienegas? If individuals along only one of the trajectories shown in Fig. 8 are capable of molarization to the degree seen at Cuatro Cienegas, this raises the possibility of a gene or genes that control not only the 
magnitude of a trait, but also the degree of variability in the trait in response to an environmental cue (Scheiner, 1993; Schlichting \& Pigliucci, 1993; Via et al., 1995). Genetics initially determine which trajectory an individual follows, and the degree of phenotypic plasticity that might be expressed. Following this reasoning, along one trajectory (the 'papilliform' trajectory) diet may perturb morphology slightly, but along the other (the 'molariform' trajectory) diet may severely affect morphology. The magnitude of phenotypic response to a particular environmental cue is thus also genetically determined.

Within broods, despite there being few significant diet effects, ANCOVA indicated many instances of significant diet $\times$ size interaction. Diet $\times$ size interaction means that slopes of growth trajectories of individuals within a brood fed different diets are not the same. Thus, diet may affect growth.

It is worth considering what the differences between rates of increase of bone and tooth size mean. Bone may grow in a variety of ways (Sissons, 1971). Bone growth and remodelling are due to the co-ordinated efforts of osteoblasts and osteoclasts. Bone may also continuously respond to external factors and may change size and material properties (Lanyon \& Rubin, 1985). Under certain circumstances, mechanical influences have been shown to regulate gene expression within bone (Raab-Cullen et al., 1994).

In contrast, teeth cannot grow or alter their morphology or material properties once they have mineralized. Changes may only be achieved via a series of discrete units produced during successive tooth generations. The mechanism by which consumption of hard food leads to molarization in fishes is still unknown. A role for mechanical influences on tooth and bone shape and robusticity has been suggested (Vandewalle et al., 1994), but the mechanism must be complex, because developing teeth in cichlids are in crypts within the bone, out of reach of direct mechanical stress (Trapani, 2001). It appears that both genetic control and 'epigenetic' factors such as mechanical stress owing to hard food consumption may play roles in determining tooth morphology.

\section{TROPHIC POLYMORPHISM OR HYBRIDIZATION: HOW MANY SPECIES OF C. MINCKLEYI?}

Smith et al. (1995) discussed the relation of various species concepts to fishes in the face of the complex and sometimes conflicting evidence available (e.g. morphology, allozymes, DNA and reproduction), and the different contextdependence of each of these parameters. They claim, following Van Valen (1976), that fish species should be recognized on the basis of lineage individuality. Lineage individuality is demonstrated by assessing morphological, genetic and reproductive independence.

Context-dependency of assortative mating (Smith et al., 1995) makes the population and genetic history of $C$. minckleyi very complex, given the large number of pools and streams these fish inhabit, their variable interconnectedness, the variety of habitats present within each, and the environmental changes in the basin over the past 50 years. Only a polythetic, 'fuzzy' species concept allows adequate handling of this kind of complexity (Van Valen, 1988).

The results of this study do not allow the question of how many species of endemic cichlids live in the Cuatro Cienegas Basin to be definitively answered; 
nonetheless, these results help clarify the predictions of the alternative hypotheses. Polymorphisms may have a basis anywhere along a continuum between entirely environmentally induced and wholly genetic (Clark, 1976); if the basis is primarily genetic, they may be under single-locus or polygenic control (Roff, 1996). Polymorphism features prominently in many ideas about speciation and adaptive radiation, often as an intermediate step during lineage divergence (Rosenzweig, 1978; West-Eberhard, 1986; Meyer, 1993; Wimberger, 1994; Schluter, 1996; Smith \& Skulason, 1996). In cichlids, assortative mating based upon colour polymorphism may occur in species also exhibiting trophic polymorphism (Wilson et al., 2000). Dental morphs of $C$. minckleyi display a variety of colours, but individuals can also change colour (G.R. Smith, pers. comm.; pers. obs.). In addition, polymorphism may be difficult to distinguish from interspecific differences, especially when populations are hybridizing (Robinson \& Schluter, 2000); C. minckleyi either constitutes one polymorphic lineage or a 'species flock' of multiple hybridizing lineages.

The problem of distinguishing polymorphism from interspecific differences has often been considered as a question of whether morphs deserve specific status. Criteria used to answer this question have included relative amounts of genetic divergence and patterns of correlated characters between morphs at different localities. The presence of a single polymorphic species is indicated by greater similarity between different morphs at the same locality than between the same morph at different localities. The alternative, greater similarity across the same morph at different localities than between different morphs at the same locality, is taken as evidence of the presence of more than one lineage (Sage \& Selander, 1975; Grudzien \& Turner, 1984).

These criteria, in addition to the minimal biochemical differences between morphs (Kornfield \& Koehn, 1975) are evidence that C. minckleyi comprises a single, polymorphic species. Clearly distinct species, however, may show genetic variability indicative of polymorphism within restricted hybrid zones, owing to differences in interlocality selection pressures (Borowsky, 1977; Grudzien \& Turner, 1984; Dowling et al., 1989). Furthermore, the biochemical evidence provided by Sage \& Selander (1975) includes data for seven proteins, two of which show fixation in at least one morph and polymorphism in others. It is unlikely that a locus could be fixed in some morphs and polymorphic in others if gene flow between morphs is substantial (McPhail, 1984). Non-assortative mating between different morphs (Kornfield et al., 1982) is evidence against separate, independent lineages.

This study indicates that trophic morphology in C. minckleyi has both genetic and environmental components, but prior studies have considered the polymorphism to be wholly genetic and under single-locus control (Sage \& Selander, 1975; Kornfield \& Taylor, 1983). Under the latter hypothesis, the presence of intermediates becomes problematic.

Most prior work on $C$. minckleyi identified few or no individuals with intermediate morphology in the field. Kornfield \& Taylor (1983) noted a low percentage of fish with intermediate morphologies, and remarked that 'the genetic basis for intermediacy is unknown, but cannot be owing to hybridization in the conventional sense'. A very low occurrence of intermediates and very little frequency fluctuation has been noted in this species (W.L. Minckley, pers. comm.). Lack of recognition of intermediates in some other studies may be owing to a variety of factors: relatively small sample sizes, lack of appropriately complex multivariate statistical methodology 
to assess variation and confusion regarding number of morphs. This study revealed several individuals $\left(c .15\right.$ out of 180 individuals $>50 \mathrm{~mm} L_{\mathrm{S}}$ ) with phenotypes intermediate between the two morphs [Fig. 5(a)]. Mating between morphs has been documented in the field (Kornfield et al., 1982), but morphological intermediates as the result of those matings are not expected under a hypothesis of a polymorphism controlled by a single locus and two alleles.

Trophic morphologies of many individuals raised in the laboratory plotted between spaces occupied by individuals of comparable size collected from Cuatro Cienegas (Fig. 9). This might be interpreted to be evidence of hybridization, and possibly introgression (Anderson, 1949). The observation that laboratory individuals are not molarized to the extent seen at Cuatro Cienegas indicates that the intermediate morphology of many laboratory individuals reflects their possession of a 'molariform' genetic background in the absence of the proper environmental cue (i.e. hard snails). The same explanation may account for the presence of a low frequency of intermediates in wild populations.

If crosses uniformly produced the full range of morphologies, polymorphism under polygenic, non-threshold control and maintained by disruptive selection (Mather, 1955) might be indicated. 'Polymorphisms' under polygenic, nonthreshold control that are not maintained when 'morphs' are crossed, however, would constitute interspecific differences.

Further experiments in which parental and offspring morphologies can be directly compared, and in which a range of food hardnesses comparable to that at Cuatro Cienegas are used, will provide a more thorough understanding of patterns of inheritance, number of genes contributing to trophic morphology and genotype $\times$ environment interactions. If offspring raised on diets similar to parental diets show intermediate morphologies, or if observed phenotypic frequencies deviate significantly from those predicted by the genetic model, the hypothesis of interspecific hybridization would be supported. The absence of such evidence would indicate that $C$. minckleyi is a single species exhibiting trophic polymorphism with both genetic and environmental components.

I thank G.R. Smith for reading earlier drafts of this paper, improving the focus and the text, and helping me evaluate a very challenging system. J.N. Taylor collected the experimental broods, raised them in the laboratory, and shared details of the experimental design. I. Kornfield sent specimens for use in this study. E. Carson, T.E. Dowling, I. Kornfield, R.R. Miller, W.L. Minckley and J.N. Taylor provided additional discussion. A. Meyer and two anonymous referees provided useful criticism of the manuscript. D. Nelson assisted in locating material in the UMMZ collections; M.E. Douglas and T.E. Dowling provided access to the ASU collections. M.L. Zelditch and P. Wilf provided statistical advice and computing aid. I. Zalmout aided in photography. I was funded by a National Science Foundation Graduate Fellowship during the course of this work.

\section{References}

Anderson, E. (1949). Introgressive Hybridization. New York: John Wiley.

Bookstein, F. L., Chernoff, B., Elder, R. L., Humphries, J. M., Smith, G. R. \& Strauss, R. E. (1985). Morphometrics in Evolutionary Biology. Ann Arbor, MI: The Academy of Natural Sciences of Philadelphia.

Borowsky, R. (1977). Detection of the effects of selection on protein polymorphisms in natural populations by means of a distance analysis. Evolution 31, 341-346. 
Clark, W. C. (1976). Environment and genotype in polymorphism. Zoological Journal of the Linnean Society 58, 255-262.

Dowling, T. E., Smith, G. R. \& Brown, W. R. (1989). Reproductive isolation and introgression between Notropis cornutus and Notropis chrysocephalus (Family Cyprinidae): comparison of morphology, allozymes, and mitochondrial DNA. Evolution 43, 620-634.

Greenwood, P. H. (1965). Environmental effects on the pharyngeal mill of a cichlid fish, Astatoreochromis alluaudi, and their taxonomic implications. Proceedings of the Linnean Society of London 176, 1-10.

Greenwood, P. H. (1981). Species-flocks and explosive evolution. In Chance, Change, and Challenge: The Evolving Biosphere (Forey, P. L., ed.), pp. 61-74. London: British Museum of Natural History.

Grudzien, T. A. \& Turner, B. J. (1984). Direct evidence that the Ilyodon morphs are a single biological species. Evolution 38, 402-407.

Humphries, J. M., Bookstein, F. L., Chernoff, B., Smith, G. R., Elder, R. L. \& Poss, S. G. (1981). Multivariate discrimination by shape in relation to size. Systematic Zoology 30, 291-308.

Huysseune, A. (1995). Phenotypic plasticity in the lower pharyngeal jaw dentition of Astatoreochromis alluaudi (Teleostei: Cichlidae). Archives of Oral Biology 40, 1005-1014.

Huysseune, A., Sire, J.-Y. \& Meunier, F. J. (1994). Comparative study of lower pharyngeal jaw structure in two phenotypes of Astatoreochromis alluaudi (Teleostei: Cichlidae). Journal of Morphology 221, 25-43.

Kornfield, I. \& Koehn, R. K. (1975). Genetic variation and speciation in New World cichlids. Evolution 29, 427-437.

Kornfield, I. \& Taylor, J. N. (1983). A new species of polymorphic fish, Cichlasoma minckleyi, from Cuatro Cienegas, Mexico (Teleostei: Cichlidae). Proceedings of the Biological Society of Washington 96, 253-269.

Kornfield, I., Smith, D. C., Gagnon, P. S. \& Taylor, J. N. (1982). The cichlid fish of Cuatro Cienegas, Mexico: direct evidence of conspecificity among distinct trophic morphs. Evolution 36, 658-664.

LaBounty, J. F. (1974). Materials for the revision of cichlids from northern Mexico and southern Texas, U.S.A. (Perciformes: Cichlidae). Unpublished PhD Dissertation, Arizona State University.

Lanyon, L. E. \& Rubin, C. T. (1985). Functional adaptation in skeletal structures. In Functional Vertebrate Morphology (Hildebrand, M., Bramble, D. M., Liem, K. F. \& Wake, D. B., eds), pp. 1-25. Cambridge: Belknap.

Liem, K. F. \& Kaufman, L. S. (1984). Intraspecific macroevolution: functional biology of the polymorphic cichlid species Cichlasoma minckleyi. In Evolution of Fish Species Flocks (Echelle, A. A. \& Kornfield, I., eds), pp. 203-215. Orono: University of Maine at Orono Press.

Mather, K. (1955). Polymorphism as an outcome of disruptive selection. Evolution 9, 52-61.

McPhail, J. D. (1984). Ecology and evolution of sympatric sticklebacks (Gasterosteus): morphological and genetic evidence for a species pair in Enos Lake, British Columbia. Canadian Journal of Zoology 62, 1402-1408.

Meyer, A. (1987). Phenotypic plasticity and heterochrony in Cichlasoma managuense (Pisces, Cichlidae) and their implications for speciation in cichlid fishes. Evolution 41, 1357-1369.

Meyer, A. (1990a). Ecological and evolutionary consequences of the trophic polymorphism in Cichlasoma citrinellum (Pisces: Cichlidae). Biological Journal of the Linnean Society 39, 279-299.

Meyer, A. (1990b). Morphometrics and allometry in the trophically polymorphic cichlid fish, Cichlasoma citrinellum: alternative adaptations and ontogenetic changes in shape. Journal of Zoology 221, 237-260.

Meyer, A. (1993). Trophic polymorphisms in cichlid fish: do they represent intermediate steps during sympatric speciation and explain their rapid adaptive radiation? In Trends in Ichthyology (Schroder, J. H., Bauer, J. \& Schartle, M., eds), pp. 257-266. Oxford: Blackwell Scientific.

Meyer, E. R. (1973). Late Quaternary paleoecology of the Cuatro Cienegas Basin, Coahuila, Mexico. Ecology 54, 982-995. 
Minckley, W. L. (1969). Environments of the Bolson of Cuatro Cienegas, Coahuila, Mexico. University of Texas at El Paso Science Series 2, 1-65.

Minckley, W. L. (1984). Cuatro Cienegas fishes: research review and a local test of diversity versus habitat size. Journal of the Arizona-Nevada Academy of Science 19, 13-21.

Neff, N. A. \& Smith, G. R. (1978). Multivariate analysis of hybrid fishes. Systematic Zoology 28, 176-196.

Raab-Cullen, D. M., Thiede, M. A., Peterson, D. N., Kimmel, D. B. \& Recker, R. R. (1994). Mechanical loading stimulates rapid changes in periosteal gene expression. Calcified Tissue International 455, 473-478.

Robinson, B. W. \& Wilson, D. S. (1996). Genetic variation and phenotypic plasticity in a trophically polymorphic population of pumpkinseed sunfish (Lepomis gibbosus). Evolutionary Ecology 10, 631-652.

Robinson, B. W. \& Schluter, D. (2000). Natural selection and the evolution of adaptive genetic variation in northern freshwater fishes. In Adaptive Genetic Variation in the Wild (Mousseau, T. A., Sinervo, B. \& Endler, J., eds), pp. 65-94. Oxford: Oxford University Press.

Roff, D. A. (1996). The evolution of threshold traits in animals. Quarterly Review of Biology 71, 3-35.

Rohlf, F. J. \& Bookstein, F. L. (1987). A comment on shearing as a method for size correction. Systematic Zoology 36, 356-367.

Rosenzweig, M. L. (1978). Competitive speciation. Biological Journal of the Linnean Society 10, 275-289.

Sage, R. D. \& Selander, R. K. (1975). Trophic radiation through polymorphism in cichlid fishes. Proceedings of the National Academy of Sciences of the United States of America 72, 4669-4673.

Scheiner, S. M. (1993). Genetics and evolution of phenotypic plasticity. Annual Review of Ecology and Systematics 24, 35-68.

Schlichting, C. D. \& Pigliucci, M. (1993). Control of phenotypic plasticity via regulatory genes. American Naturalist 142, 366-370.

Schluter, D. (1996). Ecological causes of adaptive radiation. American Naturalist 148, S40-S64.

Sissons, H. A. (1971). The growth of bone. In The Biochemistry and Physiology of Bone (Bourne, G. H., ed.), pp. 145-180. New York: Academic Press.

Smith, G. R., Rosenfield, J. \& Porterfield, J. (1995). Processes of origin and criteria for preservation of fish species. American Fisheries Society Symposium 17, 44-57.

Smith, T. B. \& Skulason, S. (1996). Evolutionary significance of resource polymorphisms in fishes, amphibians, and birds. Annual Review of Ecology and Systematics 27, $111-138$.

Smits, J. D., Witte, F. \& VanVeen, F. G. (1996). Functional changes in the anatomy of the pharyngeal jaw apparatus of Astatoreochromis alluaudi (Pisces, Cichlidae), and their effects on adjacent structures. Biological Journal of the Linnean Society 59, 389-409.

Stephens, M. (1997). Notes on the natural history of the Cuatro Cienegas cichlid, Cichlasoma minckleyi. Cichlid News 6, 26-29.

Stephens, M. J. \& Hendrickson, D. A. (2001). Larval development of the Cuatro Cienegas cichlid, Cichlasoma minckleyi. Southwestern Naturalist 46, 16-22.

Taylor, D. W. \& Minckley, W. L. (1966). New world for biologists. Pacific Discovery 19, 18-22.

Trapani, J. (2001). Location of developing replacement teeth in teleosts. Copeia 2001, 35-51.

Vandewalle, P., Huysseune, A., Aerts, P. \& Verraes, W. (1994). The pharyngeal apparatus in teleost feeding. In Biomechanics of Feeding in Vertebrates (Bels, V. L., Chardon, M. \& Vandewalle, P., eds), pp. 59-92. Berlin: Springer.

Van Valen, L. (1976). Ecological species, multi-species, and oaks. Taxon 25, 233-239.

Van Valen, L. (1988). Species, sets, and the derivative nature of philosophy. Biology and Philosophy 3, 49-66.

Via, S., Gomulkiewicz, R., De Jong, G., Scheiner, S. M., Schlichting, C. D. \& Van Tienderen, P. H. (1995). Adaptive phenotypic plasticity: consensus and controversy. Trends in Ecology and Evolution 10, 212-217. 
West-Eberhard, M. J. (1986). Alternative adaptations, speciation, and phylogeny (a review). Proceedings of the National Academy of Sciences of the United States of America 83, 1388-1392.

Wilson, A. B., Noack-Kunnmann, K. \& Meyer, A. (2000). Incipient speciation in sympatric Nicaraguan crater lake cichlid fishes: sexual selection versus ecological diversification. Proceedings of the Royal Society of London B 267, 2133-2141.

Wimberger, P. H. (1991). Plasticity of jaw and skull morphology in the Neotropical cichlids Geophagus brasiliensis and G. steindachneri. Evolution 45, 1545-1563.

Wimberger, P. H. (1992). Plasticity of fish body shape. The effects of diet, development, family and age in two species of Geophagus (Pisces: Cichlidae). Biological Journal of the Linnean Society 45, 197-218.

Wimberger, P. H. (1994). Trophic polymorphisms, plasticity, and speciation in vertebrates. In Theory and Application in Fish Feeding Ecology (Stouder, D. J., Fresh, K. L. \& Feller, R. J., eds), pp. 19-43. Columbia: University of South Carolina Press.

Witte, F. (1984). Consistency and functional significance of morphological differences between wild-caught and domestic Haplochromis squamipinnis (Pisces, Cichlidae). Netherlands Journal of Zoology 34, 596-612.

\section{Electronic Reference}

Earthwatch Project (1999). Habitat use by Cichlasoma Minckleyi, a polymorphic cichlid endemic to the Cuatro Cienegas basin of Coahuila, Mexico. http://www.utexas.edu/ Departments/tnhc/fish/cc-research/pub/earthwatch/data/behavior/morph_behavior. html. 